\title{
Effect of Direct Laser Deposition on Microstructure and Mechanical Properties of 316L Stainless Steel
}

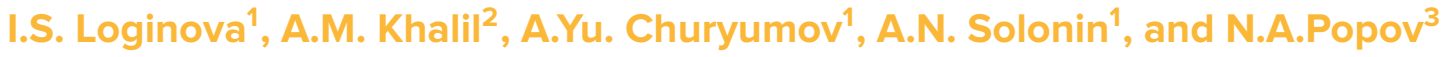 \\ ${ }^{1}$ NUST "MISiS", 119049 Russian Federation, Moscow, Leninskiy ave. 4, \\ 22 Benha University, Shoubra Faculty of Engineering, Egypt \\ ${ }^{3}$ Ural Federal University named after the First President of Russia B. N. Yeltsin, Ekaterinburg, \\ Russia
}

\section{Abstract}

Direct laser deposition (DLD) is a modern prototyping manufacturing technology, which can directly build full-density and high-performance complex metal parts This paper presents an investigation of the influence different scanning strategy on microstructure and mechanical properties of DLD 316L stainless steel sample. The results showed that formation of fine equiaxed austenitic structure with average grain size of the dendritic

Corresponding Author:

I.S. Loginova

i-popkova@list.ru

Received: 25 February 2019

Accepted: 9 April 2019

Published: 15 April 2019

Publishing services provided by

Knowledge E

(c) I.S. Loginova et al. This article is distributed under the terms of the Creative Commons

Attribution License, which permits unrestricted use and redistribution provided that the original author and source are credited.

Selection and Peer-review under the responsibility of The Ural school-seminar of metal scientists-young researchers Conference Committee. cells in 1.2-1.7 $\mu \mathrm{m}$. Inter-track idle time has directly influence on cooling rate, grain size and mechanical properties. It was shown that the decreasing of inter-track idle time from 4.37 to $0.75 \mathrm{~s}$ decreases the ultimate tensile strength from 729 to $686 \mathrm{MPa}$. For obtaining high mechanical properties of samples or recovering surfaces it is necessary to choose scanning strategy along the largest dimension of the detail.

Keywords: X-ray analysis; Electron microscopy; Stress/Strain measurements; Iron alloys; Laser/Powder methods.

\section{Introduction}

Direct laser deposition (DLD) is powder-fed technology that is differ of conventional manufacturing processes in that the material-metallic powder is added to form a desired solid geometry instead of subtracted, as in conventional machining processes [1]. As one of the advanced additive manufacturing technologies, it can be used to fabricate functional details of complex shape that are difficult or impossible process by conventional machining processes $[2,3]$. Such details can be characterized with fine structure (grain size less than $2 \mu \mathrm{m}$ ), the presence of crystallographic texture and porosity. DLD is also used to recover surface of metallic components applying in the aerospace, defense, power generation, and general manufacturing industries. It is important to understand how the 
powders and the DLD process parameters. There are special requirements (homogeneous chemical composition, spherical shape with particle size from 45 to $80 \mu \mathrm{m}$ ) which are related to the metallic powders due to design feature of the powder delivery nozzles. In modern machines, the powder nozzles diameter depends on the type of construction (lateral or off-axis, continuous coaxial, discontinuous coaxial) and varies from 1.5 to 5 $\mathrm{mm}$. To prevent the narrow nozzle opening from "clogging" the powder must have good flow rate and compaction, which is ensured by the spherical shape of the particles. Chromium-nickel austenitic stainless steel $316 \mathrm{~L}$ is of particular interest as a structural material due to its good ductility, toughness and corrosion resistance. In many papers [1-10] 316L additive manufactured stainless steel was an object of research. Mechanical properties, microstructure, lattice defects in DLD details depend on deposition process parameters (laser power, powder feed rate, traverse speed, scanning strategy). These parameters effect on size, temperature, cooling rate and direction of heat removing of melted pool $[4,6]$. The present study focuses on the microstructural features, texture and mechanical properties (tensile strength and hardness) of DLD 316L stainless steel and its dependence on different inter-track idle time. The investigation of boundary between carbon steel substrate and 316L welded layers were carried out. These effects were investigated by fabricating dumb-bell and brick bulk samples while holding other DLD process parameters constant.

\section{Materials and Experimental Procedures}

In the present work a gas atomized $316 \mathrm{~L}$ powder was used to fabricate the experimental parts. The powder has a spherical shape (Fig. 1) with aspect ratio 1,0-2,0 (measured as the ratio of the largest to the smallest particle size $\frac{l_{\max }}{l_{\min }}$, particle size in range 35-55 $\mathrm{\mu m}$. The chemical composition was uniform and presented at the Table 1.

TABLE 1: Composition of the 316L steel powder.

\begin{tabular}{|l|c|c|c|c|c|c|}
\hline \multicolumn{7}{|c|}{ The content of alloying elements, w\% } \\
\hline $\mathrm{Cr}$ & $\mathrm{Ni}$ & Mo & Mn & $\mathrm{Si}$ & $\mathrm{C}$ & $\mathrm{Fe}$ \\
\hline $17,3 \pm 1,0$ & $11,7 \pm 0,6$ & $2,5 \pm 0,3$ & $1,7 \pm 0,2$ & $0,9 \pm 0,25$ & $<0,03$ & bal. \\
\hline
\end{tabular}

Carbon steel substrates with dimensions of $170 \times 10 \times 70 \mathrm{~mm}(\mathrm{~L} \times \mathrm{W} \times \mathrm{H})$ were used as building platforms, and the plate compositions are shown in Table 2 . The surface was polished and treated with acetone to consider the effect that the surface morphologies might have on the fabrication process. 


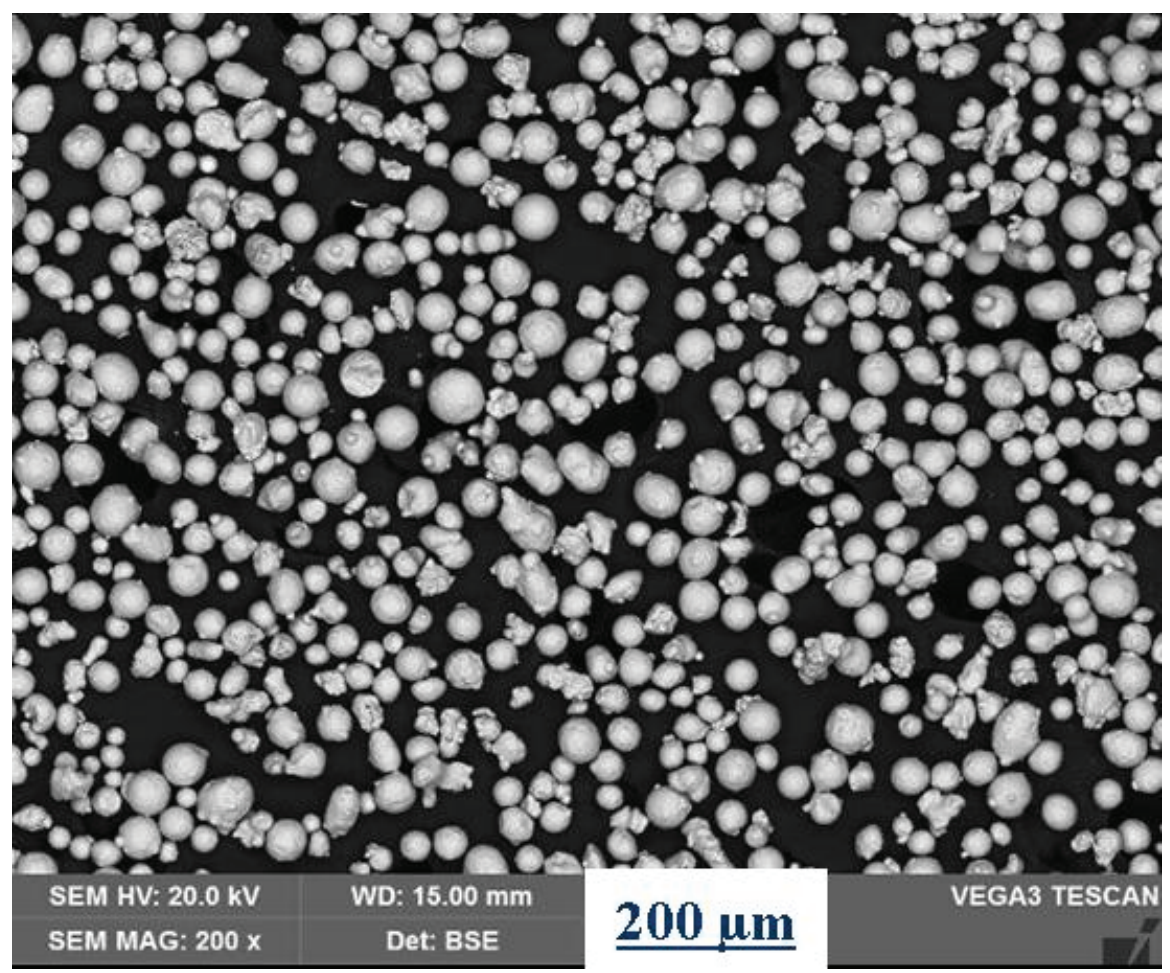

Figure 1: Particles morphology of the 316 L steel powder

TABLE 2: Composition of carbon steel plates.

\begin{tabular}{|c|c|c|c|c|}
\multicolumn{7}{c}{} & \multicolumn{4}{c}{ The content of alloying elements, w\% } \\
\hline C & $\mathrm{Mn}$ & $\mathrm{S}$ & $\mathrm{P}$ & $\mathrm{Fe}$ \\
\hline $0,3 \pm 0,1$ & $<0,3$ & $<0,03$ & $<0,01$ & bal. \\
\hline
\end{tabular}

In this work a coaxial nozzle (diameter $1,9 \mathrm{~mm}$ ) was associated with a 3 axes machine and a $3500 \mathrm{~W}$ fiber laser LS-3.5 (Ytterbium Fiber Laser System) for which diameter was $370 \mu \mathrm{m}$ and the wave length was $1064 \mathrm{~nm}$. A shielding gas argon flow carries the powder with feed rate $0,013 \mathrm{~g} / \mathrm{s}$ while a secondary gas argon flow shapes the powder stream. The laser beam was focused on the steel plate surface while the working distance between the nozzle and the focus plan remains constant at $3 \mathrm{~mm}$. In order to obtain a part with a good dimensional accuracy and a uniform surface $[5,6]$, the diameter of laser spot was $0,5 \mathrm{~mm}$ and the thickness single-track laser cladding was $0,2 \mathrm{~mm}$. The singletrack overlap ratio was set as $15 \%$, which has been successfully applied to accurately fabricate metal parts by DLD [7].

Energy density function $\psi[8,9]$ was used to optimize the parameters for DLD-process of 316L stainless steel for reason that the scanning speed and laser power, that were recommended in other studies $[8,10]$ can not be applied due to other possibilities of the machine used in this work. Thus laser power $250 \mathrm{~W}$ and scanning rate $16 \mathrm{~mm} / \mathrm{s}$ were 
selected and energy density function $156 \mathrm{~J} / \mathrm{mm}^{2}$ was calculated and compared with 168 $\mathrm{J} / \mathrm{mm}^{2}$ from other study [8] as fine indicator.

In order to investigate the influence of inter-track idle time on microstructure and mechanical properties dumb-bell and brick bulk samples were fabricated (Fig. 2) and lengthwise (Fig. 3a), transversal (Fig. 3b) and crosswise (Fig. 3c) scanning strategy were applied.

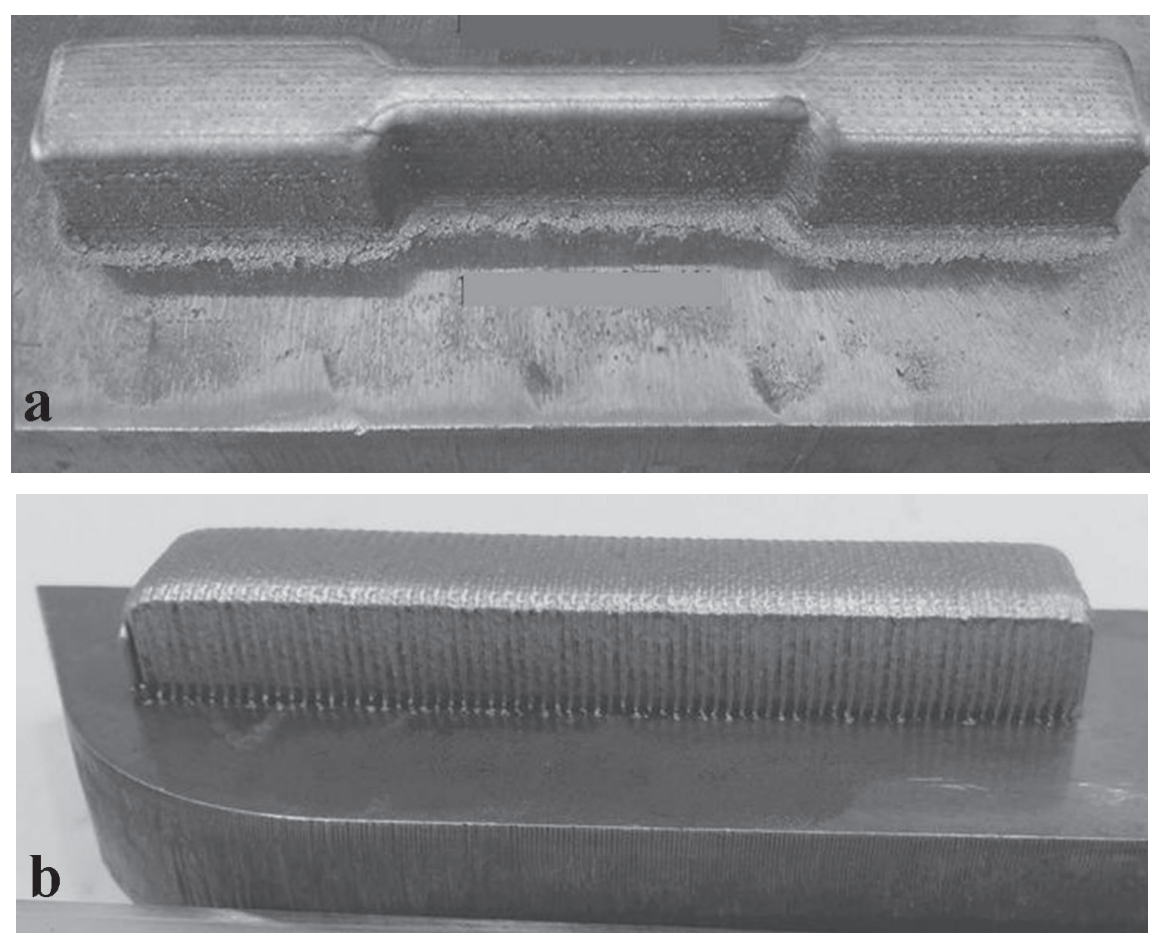

Figure 2: Dumb-bell (a) and brick (b) bulk samples.

Bulk samples were cut and machined to standard tensile test samples with $70 \mathrm{~mm}$ length, $10 \mathrm{~mm}$ width and $1 \mathrm{~mm}$ thickness for the tensile test that were examined using a Zwick Z250 tester to evaluate the tensile properties at room temperature.

Small samples from middle part were polished with colloidal silica suspension for Optical/SEM/EBSD investigations. The microstructures, crystallographic texture and orientation from these samples were examined using optical microscopy (OM) Neophot30 and scanning electron microscopy (SED) TESCAN VEGA LMH equipped with an electron back scatter diffraction (EBSD) detector Standard metallographic techniques, optical microscopy and electron scanning microscopy were used with the samples being etched with $\mathrm{HCl}-\mathrm{FeCl}_{3}$-alcohol electrolyte. Vickers hardness tests of samples were also carried out with a DIGI-TESTOR 930 hardness tester to evaluate the uniformity of the microstructure. The standard tensile test pieces of DLD samples. 
a

laser beem Powder
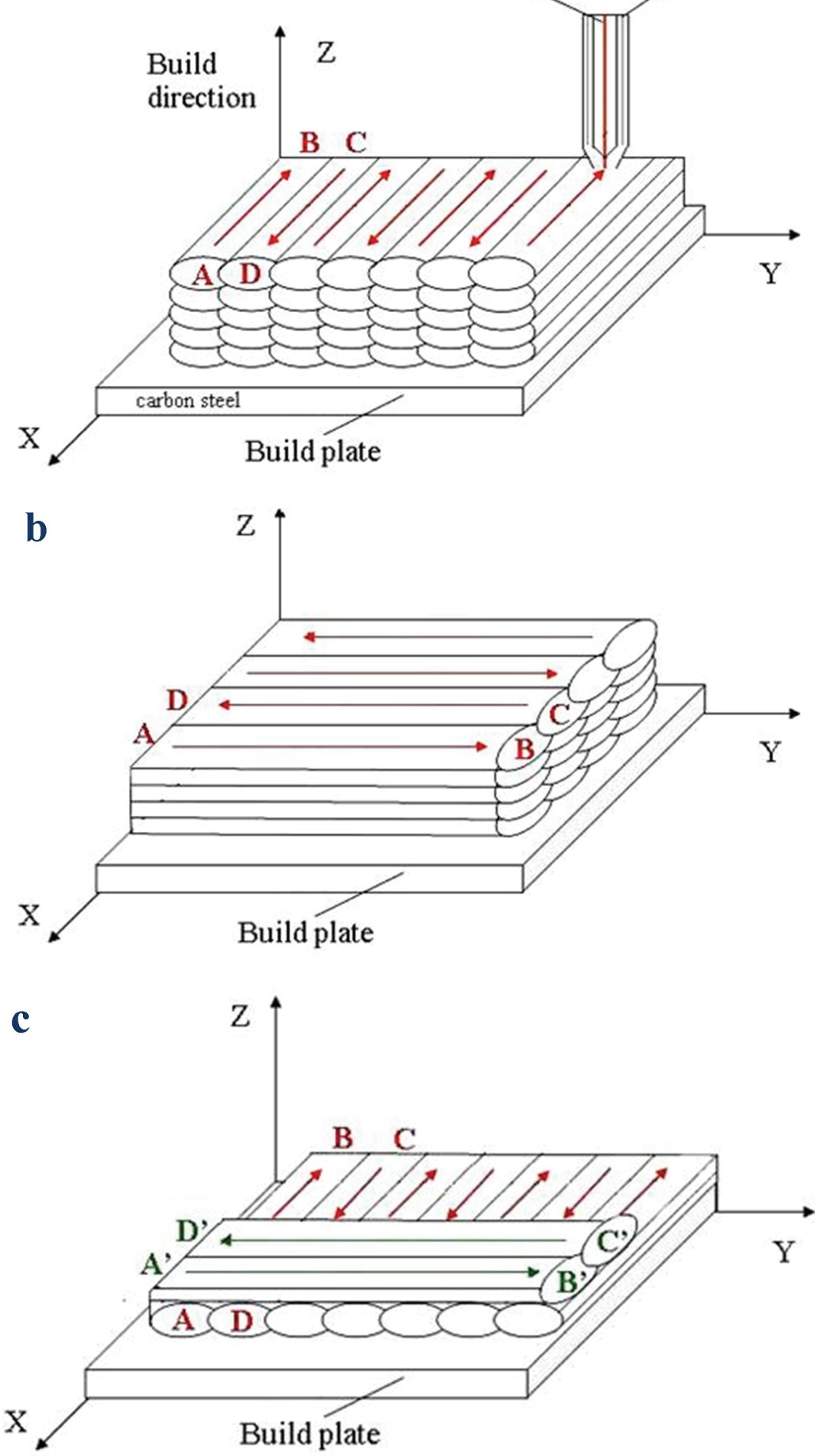

Figure 3: Lengthwise (a), transversal (b) and crosswise (c) scanning strategy. 


\section{Results and Discussion}

At the Fig. 4 typical X-Ray Diffraction pattern of a DLD 316L stainless steel samples is presented. The diffraction peaks indicate that the material consists of a pure austenitic phase.

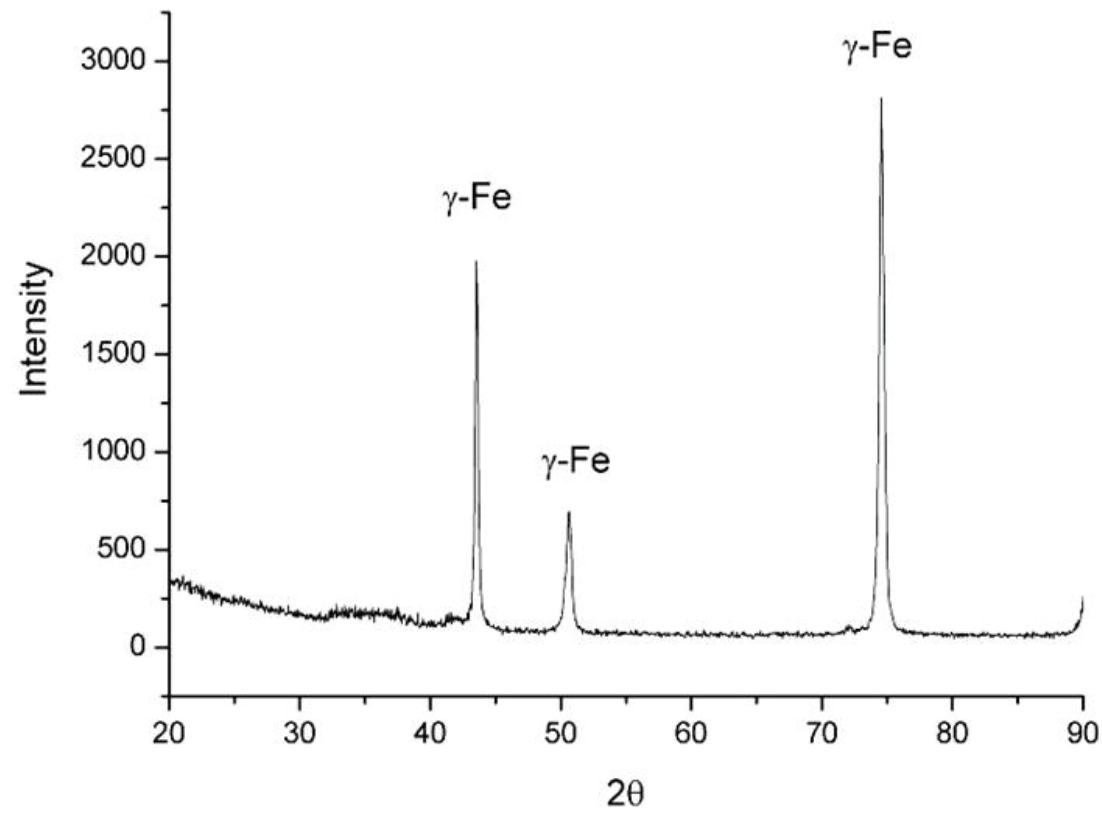

Figure 4: X-Ray Diffraction pattern of a DLD 316L stainless steel samples.

When the content of $\mathrm{Cr}$ and $\mathrm{Ni}$ is equal to 17 and $11 \mathrm{wt} . \%$, a martensite temperature is low (up to $-100^{\circ} \mathrm{C}$ ), therefore, the predominance of the formation of the austenitic phase during the entire crystallization process contributes to the formation of a single-phase structure of the samples.

A representative set of micrographs demonstrates the effect of scanning strategy on the microstructure of the stainless steels fabricated by DLD is presented in Fig. 5. It can be observed from Fig. 5(a) that the solidification microstructure in the cross-section of the stainless steel fabricated at the lengthwise strategy, was homogeneous and dense without the presence of any pores. At low magnification there are arc-shaped interface layers arranged in series one above the other and overlap of tracks in one layer in the form of vertical thin bands. The obtained sample had fine equiaxed austenitic structure with average size of the dendritic cells in $1.2 \pm 0.2 \mu \mathrm{m}$. For comparison, the microstructure of the stainless steel fabricated at the transversal strategy is demonstrated in Fig. 5(b) where a noticeable change in the morphology of the microstructure can be observed. There are two types of crystals: fine columnar and fine equiaxed austenitic cells with 
average size of $1.7 \pm 0.3 \mu \mathrm{m}$ in width and of $20 \mu \mathrm{m}$ in length. In this case at the microstructure of transversal sample another cross-section of austenitic cells (length instead of wide) can be observed. Fig. 5(c) shows mixed structure in the crosswise sample. The average size of fine equiaxed dendritic cells was $1.4 \pm 0.2 \mu \mathrm{m}$. The dendritic morphologies of all samples are all composed almost fully of cells, and all the dendrites have transformed into cells. Difference in average size of dendritic cells was not high and depends on cooling rate. At the paper [11] the effect of energy density and the cooling rate on the primary cellular arm spacing were studied. It was found that as energy density monotonously increases from the level of $2.1 \mathrm{~J} / \mathrm{mm}^{2}$ to $6.1 \mathrm{~J} / \mathrm{mm}^{2}$ the values of cooling rate during solidification of alloy monotonously decrease from $4.8 \cdot 10^{6} \mathrm{~K} / \mathrm{s}$ to $2 \cdot 6 \cdot 10^{5} \mathrm{~K} / \mathrm{s}$ and the primary cellular arm spacing increases from $0,5 \mu \mathrm{m}$ to $1,3 \mu \mathrm{m}$. Thus approximately cooling rate of $10^{5} \mathrm{~K} / \mathrm{s}$ at lengthwise sample led to the formation of dendritic cells with $1,2 \mu \mathrm{m}$ size, $10^{4} \mathrm{~K} / \mathrm{s}$ at the transversal sample led to the formation of dendritic cells with $1,7 \mu \mathrm{m}$ size and $10^{4}-10^{5} \mathrm{~K} / \mathrm{s}$ in crosswise sample led to the formation of dendritic cells with $1,4 \mu \mathrm{m}$ size.

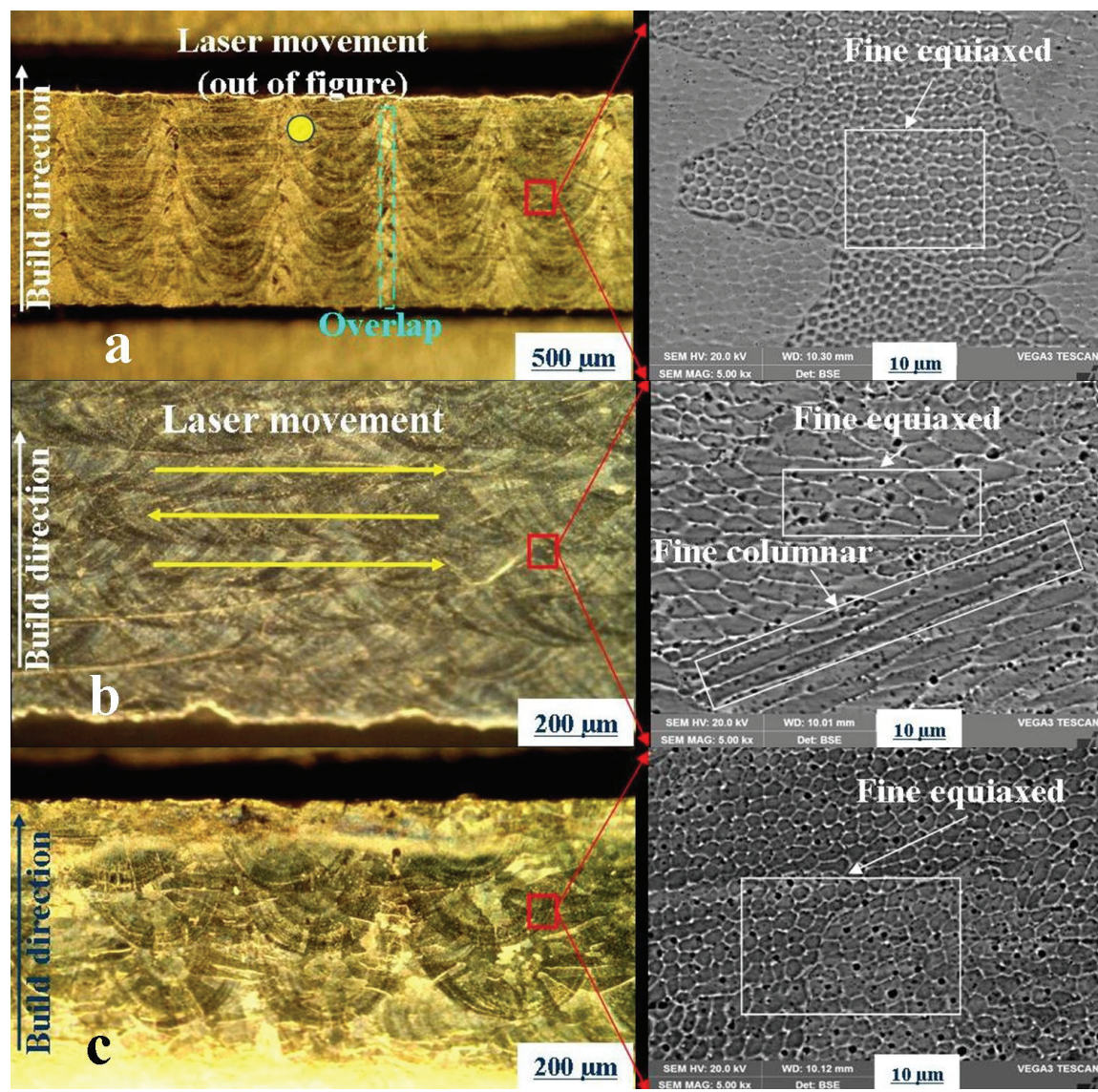

Figure 5: Microstructure at the DLD- lengthwise (a), transversal (b) and crosswise (c) samples. 
Grain size and crystallographic orientation of all samples were quantified by electron back scatter diffraction (EBSD) and presented at Fig. 6 respectively. The various colors correspond to orientation of grains with relation to crystal lattice, and each color corresponds to the unique combination of Euler angles.

The majority of grain boundaries were found to exhibit very low misorientation angles $\left(1^{\circ}-5^{\circ}\right)$ indicating a near-monocrystalline texture (Fig. 6 d,e,f). The EBSD set of micrographs were presented at Fig. 6 (a, b and c). White color of boundary at Fig. 6 (a) corresponds the overlap between of tracks at different layers at lengthwise sample and at Fig. 6 (b) white color corresponds boundary of layers at transversal sample. It was found that the grain size of accentuated in yellow color areas was bigger than in other area of the samples: $40-45 \mu \mathrm{m}$ against 70-90 $\mu \mathrm{m}$. Inter-track idle time directly effects on cooling rates, bulk temperature and melting pool size and thus the transient temperature distribution of the sample at DLD process [3, 13]. When the first track was welded, the laser turns and scan in the opposite direction, melting the second track with predetermined overlap. At the overlap area part of first track remelted and closed area heat affected. At the heat affected area metal could be quenched and tempered. Scanning strategies were chosen so that within one layer the laser beam scanning along the length (length of one track was $70 \mathrm{~mm}$ ) or along the width (length of one track was $12 \mathrm{~mm}$ ). If the length of one track is shorter, inter-track idle time smaller and the laser beam faster returns to its previous position. In this way, adjacent areas more heat affected and heat removing into the sample during crystallization was reduced. Such affect have influence on cooling rate that decreased which leads to an increase of austenite grain. It can be calculated as a ratio of length of track and scanning rate. Thus inter-track idle time was 4,37 s in lengthwise sample and 0,75 s in transversal sample. Thus, the lengthwise sample had smaller heat affected in compare to the transversal sample that affected to the final grain size and the mechanical properties of these samples.

Lengthwise sample (Fig. 2a) has the higher yield strength and ultimate tensile stress in comparing with transversal samples strength (Table 3). Crosswise sample has medium yield strength $595 \mathrm{MPa}$, ultimate tensile stress $685 \mathrm{MPa}$ and high elongation $31 \%$ Lengthwise sample has higher mechanical properties due to bigger inter-track idle time $-4,37 \mathrm{~s}$ against $0,75 \mathrm{~s}$ for transversal sample.

The mechanical properties of DLD experimental samples higher than other DLD 316L stainless steel studies. The investigation of boundary between carbon steel substrate and $316 \mathrm{~L}$ welded layers showed diffusion of $\mathrm{Cr}, \mathrm{Ni}, \mathrm{Mn}$ and $\mathrm{Mo}$ into substrate to a depth of $250 \mu \mathrm{m}$. The formation of this intermediate layer indicates that DLD process can be applied for recovering of worn surfaces of carbon steel details. 

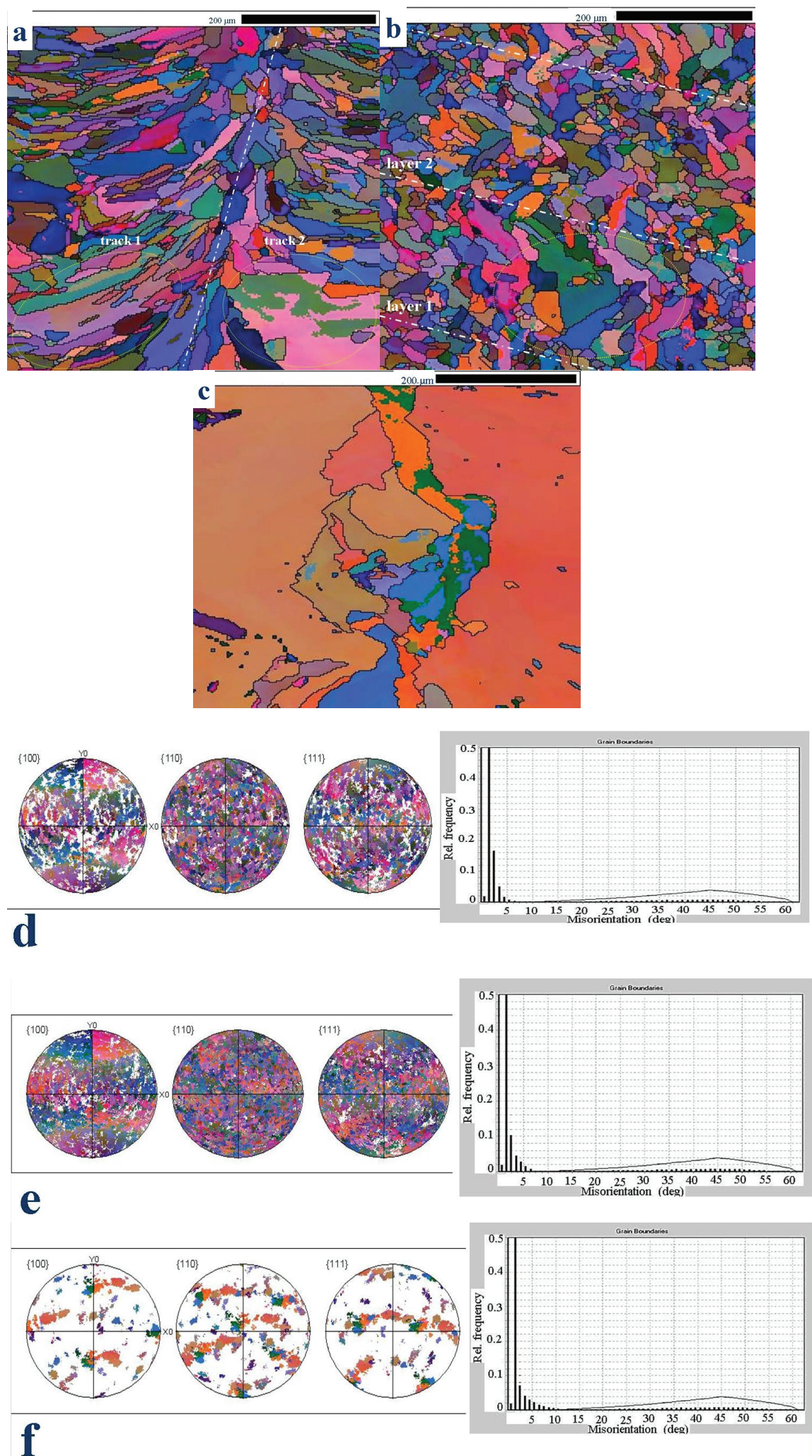

Figure 6: EBSD pole map and misorientation angle distribution of austenite phase of the lengthwise (a,d), transversal $(b, e)$ and crosswise $(c, f)$ samples. 
TABLE 3: Tensile properties of investigated DLD samples and their comparison with quenched and as well as other DLD studies $[9,15]$.

\begin{tabular}{l|c|c|c|c|}
\hline Sample & YS, MPa & UTS, MPa & $\delta, \%$ & HV \\
\hline Lengthwise & $653 \pm 19$ & $729 \pm 21$ & $25 \pm 4$ & $238 \pm 3$ \\
\hline Transversal & $574 \pm 24$ & $686 \pm 39$ & $24 \pm 8$ & $240 \pm 3$ \\
\hline Crosswise & $595 \pm 7$ & $685 \pm 21$ & $31 \pm 2$ & $234 \pm 5$ \\
\hline DLD/other studies & $330-395$ & $540-625$ & $35-85$ & - \\
\hline [3, 13] & & & & \\
\hline 316L (cast) & $240-270$ & $530-560$ & $50-55$ & - \\
\hline
\end{tabular}

\section{Summary and Conclusions}

Experimental samples were obtained using 3 different scanning strategy of DLD process. It was found that sample, obtained using lengthwise strategy, has fine equiaxed austenitic structure with average size of the dendritic cells $1.2 \pm 0.2 \mu \mathrm{m}$ while the microstructure of transversal sample consisted of fine columnar and fine equiaxed austenitic cells with average size $1.7 \pm 0.3 \mu \mathrm{m}$ in width and $20 \mu \mathrm{m}$ in length. At the crosswise sample average size of dendritic cells was $1.4 \pm 0.2 \mu \mathrm{m}$. Differences between size of dendritic cells directly depends on cooling rate that approximately were $10^{4}$ $10^{5} \mathrm{~K} / \mathrm{s}$ although all DLD process parameters were constant. The main reason was different scanning strategy of laser beam that influence of inter-track idle time and, as the result, on microstructure and mechanical properties. It was shown that as inter-track idle time change from 4.37 to $0.75 \mathrm{~s}$ the ultimate tensile strength decrees from 729 to $686 \mathrm{MPa}$. Thus for obtaining high mechanical properties of DLD samples it is necessary to choose scanning strategy along the largest dimension of the detail to increase intertrack idle time.

\section{Acknowledgements}

This work was supported by the Ministry of Education and Science of Russian Federation in the framework of Increse Competitivness Program of NUST "MISiS" and within the framework of the project on creation of high-tech manufacturing "Creation of materialeffective manufacturing of aluminium alloy powders and development of additive technologies for the produce of parts for aircraft control systems" 


\section{References}

[1] M. Brandt, The role of lasers in additive manufacturing, PlaceNameRMIT PlaceTypeUniversity, CityMelbourne, VIC, country-regionplaceAustralia, 2017;

[2] X. Wang, D. Deng, M. Qi, H. Zhang, Influences of deposition strategies and oblique angle on properties of AISI316 L stainless steel oblique thin-walled part by direct laser fabrication, Optics and Laser Tech. 80 (2016) 138-144;

[3] B. Zhang, L. Dembinski, Ch. Coddet, The study of the laser parameters and environment variables effect on mechanical properties of high compact parts elaborated by selective laser melting 316L powder, Mater. Sci. country-regionplaceEng. A 584 (2013) 21-31;

[4] A. Yadollahia, N. Shamsaei, S.M. Thompson, D.W. Seely, Effects of process time interval and heat treatment on the mechanical and microstructural properties of direct laser deposited 316L stainless steel, Mater. Sci. country-regionplaceEng. A 644 (2015) 171-183;

[5] H.E. Cheikh, B. Courant, S. Branchu, X.Huang, J.-Y. Guillen. Direct Laser Fabrication process with coaxial powder projection of 316L steel. Geometrical characteristics and microstructure characterization of wall structure. Opt. Las. placecountry-regionEng. 50 (2012) 1779-1784;

[6] T. Marcua, M. Todeab, placel. Gligora, P. Popa. Effect of surface conditioning on the flowability of Ti6AI7Nb powder for selective laser melting applications. Applied Surface Science 258 (2012) 3276-3282;

[7] M. Man, Z. Wang, D. Wang, X. Zeng, Control of shape and performance for direct laser fabrication of precision large-scale metal parts with 316L Stainless Steel, Optics and Laser Tech. 45 (2013) 209-216;

[8] N. Read, placeW. Wang; Selective laser melting of AISi10Mg alloy: Process optimization and mechanical properties development, Mater. Des.65 (2015) 417-424;

[9] S.M. Thompson, L. Bian, placeN. Shamsaei, A. Yadollahi, An overview of Direct Laser Deposition for additive manufacturing; Part I: Transport phenomena, modeling and diagnostics, Addit. Manuf. 8 (2015) 36-62;

[10] H.E. Cheikh, B. Courant, S. Branchu, X. Huanc, J.-Y. Hascoet, R. Guillen, Direct Laser Fabrication process with coaxial powder projection of 316L steel. Geometrical characteristics and microstructure characterization of wall structures. Opt. Las. placecountry-regionEng. 50 (2012) 1779-1784;

[11] L.Costa, R.Vilar, T.Reti, A.M.Deus, Rapid tooling by laser powder deposition: Process simulation using finite element analysis, Acta Mater. 53 (2005) 3987-3999; 
[12] Mingming Ma, Zemin Wang, Xiaoyan Zeng, A comparison on metallurgical behaviors of 316 L stainless steel by selective laser melting and laser cladding deposition, Mater. Sci. country-regionplaceEng. A 685 (2017) 265-273;

[13] B. Zheng, Y. Zhou, J.E. Smugeresky, J.M. Schoenung, E.J. Lavernia, Thermal behavior and microstructure evolution during laser deposition with laser engineered net shaping: part II. experimental investigation and discussion, Metall. Mater.Trans.A.39 (2008) 2237-2245;

[14] J.W. Fu, Y.S. Yang, J.J. Guo, W.H. Tong, Effect of cooling rate on solidification microstructures in AISI 304 stainless steel, Mater. Sci. Technol. 24 (2008) 941-944;

[15] N. Shamsaei, A. Yadollahia, L. Bian, S.M. Thompson, An overview of Direct Laser Deposition for additive manufacturing; Part II: Mechanical behavior, process parameter optimization and control, Addit. Manuf. 8 (2015) 12-35. 